\title{
Blood granulocyte patterns as predictors of asthma phenotypes in adults from the EGEA study
}

\author{
Rachel Nadif ${ }^{1,2}$, Valérie Siroux ${ }^{3,4,5}$, Anne Boudier ${ }^{3,4,5}$, Nicole le Moual ${ }^{1,2}$, \\ Jocelyne Just' ${ }^{6}$. Frederic Gormand ', Christophe Pison '8,9,10, Regis Matran' ${ }^{11,12}$ \\ and Isabelle Pin $3,4,5$
}

\begin{abstract}
Affiliations: ${ }^{1}$ INSERM, U1168, VIMA: Ageing and Chronic Diseases, Epidemiological and Public Health Approaches, Villejuif, France. ${ }^{2}$ Univ Versailles St-Quentin-en-Yvelines, UMR-S 1168, Montigny le Bretonneux, France. ${ }^{3}$ INSERM, IAB, Team of Environmental Epidemiology Applied to Reproduction and Respiratory Health, Grenoble, France. ${ }^{4}$ Univ Grenoble Alpes, Grenoble, France. ${ }^{5} \mathrm{CHU}$ de Grenoble, Pédiatrie, Grenoble, France. ${ }^{6}$ Centre de l'Asthme et des Allergies, APHP, Hôpital Trousseau, UMPC Paris 6, Paris, France. ${ }^{7} \mathrm{CHU}$ de Lyon, Pneumology Dept, Lyon, France. ${ }^{8}$ Clinique Universitaire de Pneumologie, Pôle Thorax et Vaisseaux, CHU Grenoble, Grenoble, France. ${ }^{9}$ INSERM U1055, Grenoble, France. ${ }^{10}$ Univ Grenoble Alpes, Grenoble, France. ${ }^{11}$ Univ Lille, Lille, France. ${ }^{12} \mathrm{CHU}$, Lille, France.
\end{abstract}

Correspondence: Rachel Nadif, INSERM UMR-S 1168, VIMA: Aging and Chronic Diseases, Epidemiological and Public Health Approaches, 16, Avenue Paul Vaillant Couturier, F-94807, Villejuif, France.

E-mail: rachel.nadif@inserm.fr

ABSTRACT To what extent blood granulocyte patterns may predict asthma control remains understudied. Our aim was to study associations between blood neutrophilia and eosinophilia and asthma control outcomes in adults.

Analyses were conducted in 474 asthmatics from the first follow-up of the Epidemiological Study on the Genetics and Environment of Asthma (EGEA2), including 242 asthmatics who were adults a decade earlier (EGEA1). At EGEA2, asthma control was assessed using the Global Initiative for Asthma definition (2015), and asthma exacerbations by use of urgent care or courses of oral corticosteroids in the past year. Blood EOS ${ }^{\mathrm{lo}} / \mathrm{EOS}^{\text {hi }}$ was defined as $<1 \geqslant 250$ eosinophils $\cdot \mathrm{mm}^{-3}$, respectively, and $\mathrm{NEU}^{\mathrm{lo}} / \mathrm{NEU}^{\text {hi }}$ as $<1 \geqslant 5000$ neutrophils $\cdot \mathrm{mm}^{-3}$, respectively. Estimates were adjusted for age, sex and smoking.

At EGEA2, NEU ${ }^{\text {hi }}$ was associated with asthma exacerbations and poor asthma control $(\mathrm{OR}>2.10)$. EOS $^{\text {hi }}$ was associated with higher bronchial hyperresponsiveness (BHR) (OR (95\% CI) 2.21 (1.24-3.97)), poor lung function $(\mathrm{p}=0.02)$ and higher total IgE level $(\mathrm{p}=0.002)$. Almost $50 \%$ of asthmatics had a persistent pattern between surveys. Persistent $\mathrm{NEU}^{\text {hi }}$ was associated with poor asthma control at EGEA2 (OR (95\% CI) 3.09 (1.18-7.05)). EOS ${ }^{\text {hi }}$ at EGEA1 and persistent EOS ${ }^{\text {hi }}$ were associated with higher BHR (OR (95\% CI) $2.36(1.10-5.07)$ and 3.85 (1.11-13.34), respectively), poor lung function $(\mathrm{p}<0.06)$ and higher immunoglobulin E level $\left(\mathrm{p}<10^{-4}\right)$ at EGEA2.

Granulocyte patterns were differently associated with asthma outcomes, suggesting specific roles for each one, which could be tested as predictive signatures.

@ERSpublications

Blood eosinophils and neutrophils to help identify adults with subsequent risk of asthma burden http://ow.ly/A9KS301n0YR

Editorial comment in Eur Respir J 2016; 48: 976-978.

Received: Feb 152016 | Accepted after revision: June 132016 | First published online: Aug 042016

This article has supplementary material available from erj.ersjournals.com

Support statement: Research was funded in part by the National Hospital Programme of Clinical Research (PHRC-national 2012, EvAdA), ANR-CES-2009, Region Nord Pas-de-Calais, Merck Sharp \& Dohme, and the GA2LEN project, Global Allergy and Asthma European Network, and the Fonds AGIR pour les Maladies Chroniques. Funding information for this article has been deposited with the Open Funder Registry.

Conflict of interest: Disclosures can be found alongside this article at erj.ersjournals.com

Copyright CERS 2016 


\section{Introduction}

Although induced sputum seems to be the gold standard test for phenotyping the inflammation in asthma [1-5], the use of circulating granulocyte counts has been proposed as a more suitable method in large-scale studies [6-8].

Blood neutrophilia and eosinophilia are recognised features of asthma [9-11]. Blood eosinophils are proposed as biological markers to monitor uncontrolled asthma [12], to personalise immunological biotherapies in patients with asthma [11], to target severe asthma with increased blood eosinophils for treatment with anti-interleukin-5 antibodies [13,14] and to select appropriate patients with chronic obstructive pulmonary disease (COPD) to be treated with inhaled corticosteroids [15]. Regarding neutrophilia, recent studies have shown that neutrophils are closely associated with not only severity, but initiation of allergic inflammation and allergic sensitisation [16]. However, data to support neutrophilic asthma as a specific phenotype are rare, and no consensus exists for the level of blood neutrophilia that should be used to define this phenotype [10].

We were first to describe the use of cut-off points of 250 cells $\cdot \mathrm{mm}^{-3}$ and 5000 cells $\cdot \mathrm{mm}^{-3}$, respectively, for blood counts of eosinophils and neutrophils to define granulocyte patterns in adults in the framework of the Epidemiological Study on the Genetics and Environment of Asthma (EGEA) [6,7]. We showed that the eosinophilic pattern was associated with reports of more asthma attacks and being woken by an attack of shortness of breath in the past 12 months, and that the neutrophilic pattern was associated with fewer positive skin-prick test responses and with reports of more nocturnal symptoms and dyspnoea. A study by VolBEDA et al. [17] showed that adult patients with uncontrolled asthma had higher numbers of eosinophils in peripheral blood, whereas no association was found with blood neutrophil numbers. High blood eosinophil count $\left(\geqslant 400\right.$ cells $\left.\cdot \mathrm{mm}^{-3}\right)$ was also reported as a practical biological marker to identify adult patients with persistent asthma who are at increased risk for future asthma exacerbations [18]. And concomitant systemic $\left(\geqslant 400\right.$ cells $\left.\cdot \mathrm{mm}^{-3}\right)$ and bronchial $(\geqslant 3 \%)$ eosinophilic inflammation has been reported to contribute to poor asthma control [19]. To the best of our knowledge, no studies have reported variations over long periods of time of blood neutrophilia and eosinophilia in adults with asthma, nor investigated the long-term relationship of both the neutrophilic and eosinophilic pattern with asthma control outcomes.

In the EGEA study, using the same blood granulocyte count cut-off points as previously described, we assessed the association of blood eosinophil and neutrophil patterns with asthma control outcomes, both in a cross-sectional and longitudinal way.

\section{Methods}

Study design

Data used for the analyses were collected in the framework of the EGEA (https://egeanet.vjf.inserm.fr/), a French cohort study based on an initial group of asthma cases and their first-degree relatives, and controls (first survey: EGEA1). The protocol and descriptive characteristics have been described previously and are included in the online supplementary material [20-22].

The cross-sectional analysis includes asthma cases and their first-degree relatives with asthma who were adults (aged $\geqslant 16$ years) at the second survey (EGEA2) with available data on blood eosinophil and neutrophil cell counts $(\mathrm{n}=232+242=474)$ (figure 1$)$. For the longitudinal analysis, asthma cases and their first-degree relatives already aged $\geqslant 16$ years a decade earlier (EGEA1; $n=381$ ), and with available data for blood eosinophil and neutrophil cell counts $(n=242)$ were included. Asthmatics included in the longitudinal analyses $(n=242)$ were more often asthma cases and current smokers than those not included in the longitudinal analyses (online supplementary table S1). The two groups did not differ for age, sex, body mass index, asthma, treatment, lung function, allergic sensitisation, immunoglobulin (Ig)E level and blood eosinophil and neutrophil counts.

Ethical approval was obtained from the relevant institutional review board committees (Cochin Port-Royal Hospital and Necker-Enfants Malades Hospital, Paris). Written informed consent was signed by all participants.

\section{Respiratory phenotypes}

Inclusion criteria used to define asthma cases were based on self-reported positive responses to four questions from the validated and standardised British Medical Research Council, European Coal and Steel Community, American Thoracic Society (ATS) and European Community Respiratory Health Survey questionnaires: "Have you ever had attacks of breathlessness at rest with wheezing?", "Have you ever had asthma attacks?", "Was this diagnosis confirmed by a physician?" and "Have you had an asthma attack in the last 12 months?", or a positive response to at least two questions and a positive review of the medical records. Asthma in relatives of cases was defined as a positive answer to at least one of the first two questions $[23,24]$. 


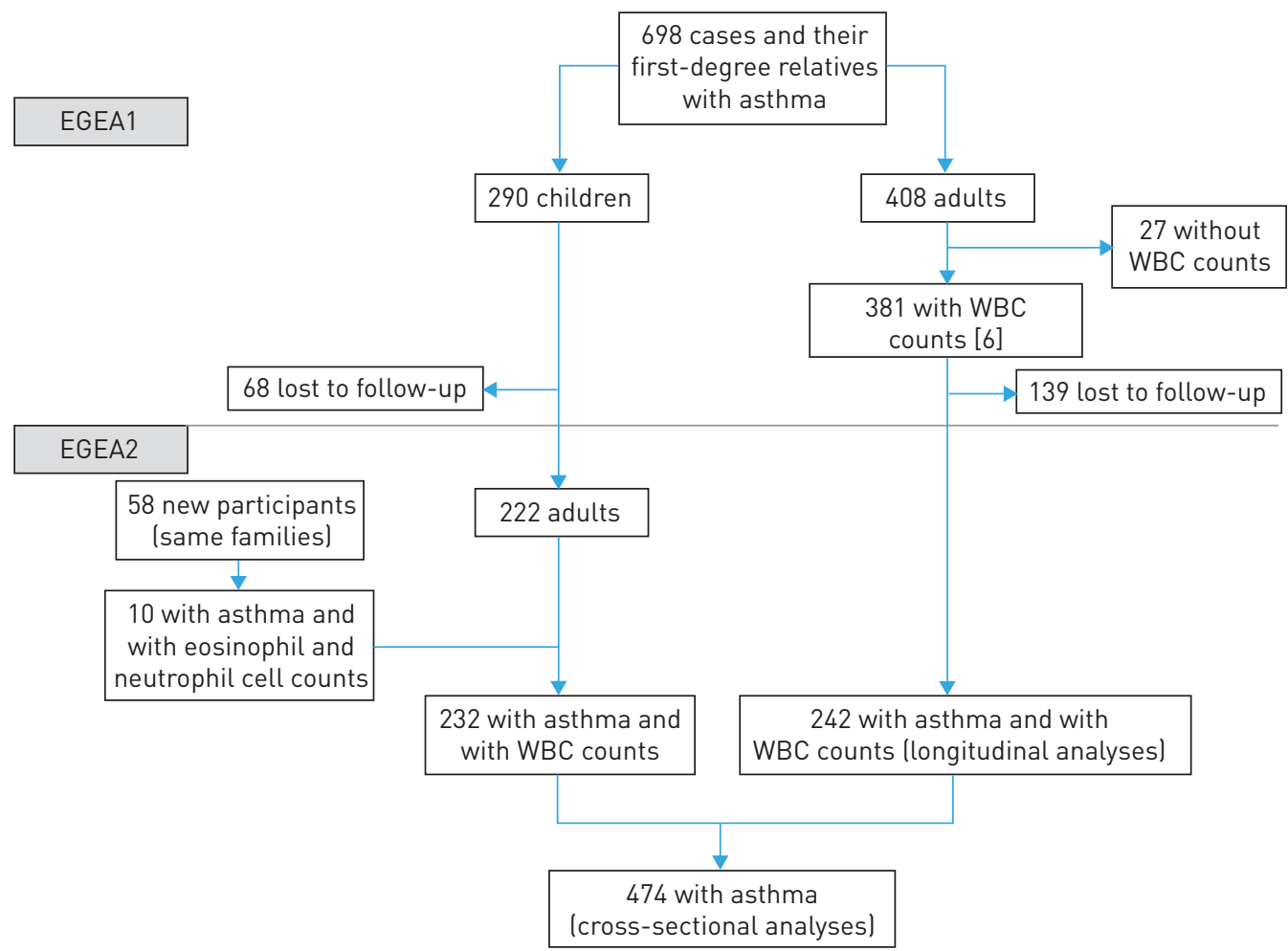

FIGURE 1 Flow chart of the participants included in the cross-sectional and longitudinal analyses. EGEA: Epidemiological Study on the Genetics and Environment of Asthma; WBC: white blood cell.

Symptom control in asthma was assessed in three classes, over a 3-month period, using responses to EGEA2 survey questions to approximate as closely as possible the Global Initiative for Asthma (GINA) 2015 definition, and as previously used [25]. Participants were defined as having controlled, partly controlled and uncontrolled asthma if they had none, 1-2 or 3-4 of the following criteria, respectively: frequent daytime symptoms (defined by at least one asthma attack or one or more instances of trouble breathing per week in the past 3 months), any night-time symptoms (defined by waking because of asthma or by an attack of shortness of breath in the past 3 months), frequent use of reliever medication (defined by on average twice a week in the past 3 months) and any activity limitation (defined by the following answer "totally limited", "extremely limited", "very limited", "moderate limitation" or "some limitation" to the question "Overall, among all the activities that you have done during the last 2 weeks, how limited have you been by your asthma?”).

Data on medication for asthma was available for 470 (99.2\%) of the participants: 286 (60.3\%) participants did not take any medication in the past 12 months. In the past 3 months, $122(25.7 \%)$ participants reported regular use of inhaled corticosteroids (ICS), and 62 (13.1\%) reported use of ICS, but not regular use. Furthermore, main daily ICS dose over the past 12 months is available for the 122 participants with a median (minimum-maximum) of $250(50-500) \mu \mathrm{g}$ of beclometasone equivalent.

Asthma exacerbation was defined at EGEA2 by hospital or emergency admissions because of respiratory problems or use of oral steroids for breathing difficulties in the past year.

A lung function test with spirometry and methacholine challenge was performed using a standardised protocol with similar equipment across centres according to the ATS/European Respiratory Society guidelines [26]. Change in forced expiratory volume in $1 \mathrm{~s}$ (FEV1) between first and second spirometry was assessed as annual lung function change ( $\mathrm{mL}$ per year) with a negative value representing a decline.

\section{Blood granulocyte patterns}

At both surveys, four granulocyte patterns were defined from white blood cell counts according to the eosinophil (EOS) and neutrophil (NEU) count cut-off points previously described [6]. Briefly, samples with $\geqslant 250$ EOS. $\mathrm{mm}^{-3}$ were classified as EOS ${ }^{\text {hi }}$, and those with $\geqslant 5000 \mathrm{NEU} \cdot \mathrm{mm}^{-3}$ as NEU ${ }^{\text {hi }}$. The cut-off point for eosinophils is the one commonly used in epidemiology, and corresponded to the 75th percentile in the 1356 adults at the EGEA1 study. Only 20 patients with asthma had a neutrophil count equal to or higher than the upper limit adult references [27], and a cut-off point of $5000 \mathrm{NEU} \cdot \mathrm{mm}^{-3}$ was chosen, 
which corresponded to the 75th percentile of the distribution. Other cut-off points were also studied: 300 and $400 \mathrm{EOS} \cdot \mathrm{mm}^{-3}$, reported in the literature, $6040 \mathrm{NEU} \cdot \mathrm{mm}^{-3}$, corresponding to the 90th percentile in the 1356 adults from the EGEA1 study and optimal cut-off points calculated using the receiver operating characteristic (ROC) curve (see the online supplementary material for more details).

\section{Statistical methods}

Standard statistical tests were performed. Due to the familial aggregation of the data, multivariate analyses (except polytomous logistic regression) were conducted using generalised estimated equations to take into account dependence between observations. Controlled asthma was the reference group. Due to similarity in results in partly controlled and uncontrolled asthma, and due to the small number of asthmatics in the uncontrolled group, asthma control was also expressed as a dichotomous variable: partly controlled plus uncontrolled versus controlled. A sensitivity analysis was performed to test associations with different cut-off points for eosinophils and neutrophils.

For the cross-sectional analyses at EGEA2, a sensitivity analysis was performed to test associations between granulocyte patterns and asthma control in participants without respiratory infections in the past 4 weeks. To investigate the modifying effect of current smoking status (smokers versus non- or ex-smokers) and ICS treatment in the past year on associations between granulocyte patterns and asthma control, analyses were conducted in the dataset stratified by each of these factors. Sensitivity analyses were also performed with adjustment for ICS use in the past 3 months expressed as three classes (no use, irregular use and regular use), with adjustment for daily dose of ICS and by excluding participants with chronic bronchitis. Moreover, to take into account the complex interplay between eosinophilia and allergic sensitisation, associations between eosinophil patterns and asthma control were further adjusted for allergic sensitisation (yes/no). For the longitudinal analysis, the association between blood granulocyte patterns at EGEA1 with the subsequent risk of poor asthma control (partly controlled or uncontrolled asthma) at EGEA2 was investigated. Persistence of the granulocyte patterns (NEU ${ }^{\text {hi }}$ at EGEA1 and 2 and EOS $^{\text {hi }}$ at EGEA1 and 2) and changes between EGEA1 and EGEA2 were also considered.

All multiple regression models considered age (continuous), sex, smoking status (never-, ex- or current smokers) and ICS treatment in the past year (yes/no) as potential confounding factors. These factors were measured at EGEA2 for the cross-sectional analyses and at EGEA1 for the longitudinal analyses (except for current smoking, for which the status over the follow-up time was also considered). All statistical analyses were performed using SAS software (version 9.4; SAS Institute, Inc., Cary, NC, USA).

\section{Results}

The overall characteristics of the participants are shown in table 1: at EGEA2, 48.9\%, 10.6\%, 31.6\% and $8.9 \%$ of them belonged to the paucigranulocytic $\left(\mathrm{EOS}^{\mathrm{lo}} / \mathrm{NEU}^{\mathrm{lo}}\right)$, neutrophilic $\left(\mathrm{EOS}^{\mathrm{lo}} / \mathrm{NEU}^{\mathrm{hi}}\right)$, eosinophilic $\left(\mathrm{EOS}^{\mathrm{hi}} / \mathrm{NEU}^{\mathrm{lo}}\right)$ and mixed $\left(\mathrm{EOS}^{\mathrm{hi}} / \mathrm{NEU}^{\mathrm{hi}}\right)$ pattern groups, respectively. These frequencies were similar among the sub-population involved in the longitudinal analyses. Characteristics of the participants according to these four blood granulocyte patterns are shown in online supplementary table S2.

Neutrophil counts were significantly higher in females, in participants with respiratory infections in the past 4 weeks and increased with age (all $\mathrm{p}<0.01$ ). Among all participants, neutrophil counts increased with the number of smoking pack-years $(\mathrm{p}=0.07)$. Among ex- and current smokers, neutrophil counts increased with the number of cigarettes smoked per day (mean (95\% CI) 4054 (3527-4235) cells.mm ${ }^{-3}, 3901$ (3511-4290) cells $\cdot \mathrm{mm}^{-3}, 4380$ (3878-4882) cells $\cdot \mathrm{mm}^{-3}$ and $4576(3724-5427)$ cells $\cdot \mathrm{mm}^{-3}$ for 0 cigarettes per day, 110 cigarettes per day, 11-20 cigarettes per day and >20 cigarettes per day, respectively; p-value for trend 0.02 ). Eosinophil and neutrophil counts were significantly higher in ICS users than in nonusers (adjusted mean $(95 \%$ CI), $288(259-317)$ cells $\cdot \mathrm{mm}^{-3}$ versus $231(206-256)$ cells $\cdot \mathrm{mm}^{-3}(\mathrm{p}=0.003)$ and $4286(4078-4493) \mathrm{cells} \cdot \mathrm{mm}^{-3}$ versus 3905 (3724-4087) cells $\cdot \mathrm{mm}^{-3}$ ( $\left.\mathrm{p}=0.006\right)$, respectively). No other significant associations were found.

Granulocyte patterns and phenotypic characteristics in cross-sectional analyses ( $n=474$ )

Participants with the NEU ${ }^{\text {hi }}$ pattern reported more nocturnal cough in the past year, more exacerbations, more chronic cough and had poorer asthma control than those with the NEU ${ }^{\text {lo }}$ pattern (table 2). They also had a nonsignificant tendency for lower FEV1 (mean (95\% CI) 92.4 (88.7-96.0)\% predicted versus 95.6 (93.5-97.7)\% pred, $\mathrm{p}=0.10)$ than those with the NEU ${ }^{\text {lo }}$ pattern. Participants with the EOS ${ }^{\text {hi }}$ pattern had higher bronchial hyperresponsiveness (BHR: lower provocative dose causing a $20 \%$ fall in FEV1) (table 2), higher total IgE level (mean (95\% CI) $213(175-261) \mathrm{IU} \cdot \mathrm{mL}^{-1}$ versus $\left.144(122-171) \mathrm{IU} \cdot \mathrm{mL}^{-1}, \mathrm{p}=0.002\right)$ and lower FEV1 (mean (95\% CI) 93.2 (90.4-96.0)\% pred versus 97.3 (95.0-99.6)\% pred, $\mathrm{p}=0.02$ ) than those with the $\operatorname{EOS}^{\text {lo }}$ pattern. No significant association was found between EOS ${ }^{\text {hi }}$ pattern and allergic sensitisation (OR (95\% CI) 1.30 (0.67-1.90)). 
TABLE 1 Characteristics of adults with asthma included in the analyses of the second survey of the Epidemiological Study on the Genetics and Environment of Asthma

\begin{tabular}{|c|c|c|}
\hline & Cross-sectional analyses & Longitudinal analyses \\
\hline Subjects $\mathrm{n}$ & 474 & 242 \\
\hline Age years & $38.2 \pm 16.1$ & $48.2 \pm 13.1$ \\
\hline Female & 47.9 & 53.3 \\
\hline \multicolumn{3}{|l|}{ Body mass index } \\
\hline$<20 \mathrm{~kg} \cdot \mathrm{m}^{-2}$ & 12.2 & 8.3 \\
\hline $20-25 \mathrm{~kg} \cdot \mathrm{m}^{-2}$ & 53.3 & 47.5 \\
\hline $25-30 \mathrm{~kg} \cdot \mathrm{m}^{-2}$ & 24.4 & 30.8 \\
\hline$\geqslant 30 \mathrm{~kg} \cdot \mathrm{m}^{-2}$ & 10.1 & 13.4 \\
\hline \multicolumn{3}{|l|}{ Smoking habits } \\
\hline Smokers & 24.0 & 16.5 \\
\hline Ex-smokers & 24.3 & 34.3 \\
\hline Nonsmokers & 51.7 & 49.2 \\
\hline \multicolumn{3}{|l|}{ Age of asthma onset } \\
\hline$\leqslant 4$ years & 31.6 & 19.4 \\
\hline $4-16$ years & 36.3 & 33.5 \\
\hline$>16$ years & 32.1 & 47.1 \\
\hline Total immunoglobulin E IU.mL $\mathrm{mL}^{-1}$ & 155 (68.7-377) & $123(48.6-304)$ \\
\hline Current asthma (past 12 months) & 89.2 & 91.3 \\
\hline Skin-prick test positivity ${ }^{\#}$ & 82.1 & 77.2 \\
\hline \multicolumn{3}{|l|}{ White blood cell counts } \\
\hline Eosinophils cells $\cdot \mathrm{mm}^{-3}$ & $259 \pm 198$ & $255 \pm 189$ \\
\hline Neutrophils cells $\cdot \mathrm{mm}^{-3}$ & $4047 \pm 1442$ & $4225 \pm 1536$ \\
\hline FEV $1 \%$ pred & $96.2 \pm 18.2$ & $93.1 \pm 21.4$ \\
\hline FEV $1<80 \%$ pred & 14.4 & 21.7 \\
\hline Methacholine challenge ${ }^{\pi} n$ & 282 & 126 \\
\hline $\mathrm{PD}_{20} \leqslant 4 \mathrm{mg}$ & 71.6 & 65.9 \\
\hline Asthma attacks in past 12 months & 41.8 & 40.9 \\
\hline \multicolumn{3}{|l|}{ Nocturnal symptoms in past 12 months } \\
\hline Cough & 37.0 & 38.0 \\
\hline Chest tightness & 22.8 & 27.3 \\
\hline Shortness of breath & 48.9 & 51.6 \\
\hline \multicolumn{3}{|l|}{ Asthma control } \\
\hline Uncontrolled & 10.6 & 13.2 \\
\hline Partly controlled & 32.7 & 33.5 \\
\hline Controlled & 56.7 & 53.3 \\
\hline Chronic cough & 12.5 & 14.5 \\
\hline Chronic phlegm & 10.8 & 12.9 \\
\hline Cough or phlegm all days during 3 months & 13.6 & 17.0 \\
\hline Dyspnoea grade 3 & 16.2 & 23.4 \\
\hline Inhaled corticosteroids in past 12 months & 44.5 & 55.6 \\
\hline Respiratory infection in past 4 weeks & 15.0 & 15.8 \\
\hline
\end{tabular}

Data are presented as mean \pm SD, $\%$ or geometric mean (interquartile range), unless otherwise stated. FEV1: forced expiratory volume in $1 \mathrm{~s}$; PD20: provocative dose causing a $20 \%$ fall in FEV1. ${ }^{\#}$ : defined by a mean weal diameter $\geqslant 3 \mathrm{~mm}$ greater than the negative control for at least one of 12 aeroallergens; ${ }^{\text {9 }}$ : not performed if baseline $\mathrm{FEV} 1<80 \%$ pred.

The association between high neutrophil inflammation and asthma control remained significant after further adjustment on eosinophil count (OR (95\% CI) 2.95 (1.74-5.00) and 3.08 (1.42-6.69) for partly controlled and uncontrolled asthma, respectively). Associations beetween neutrophil inflammation and poor asthma control (partly controlled or uncontrolled versus controlled) were consistently observed in participants without respiratory infections in the past 4 weeks, or after stratification according to current smoking status or ICS treatment (figure 2) (p-values for Breslow-Day interaction test <0.5). The associations remained also significant after adjustment on both current smoking status and ICS treatment in the past 12 months (figure 2), but also after adjustment for ICS use in the past 3 months (OR (95\% CI) 2.82 (1.73-4.62)), after adjustment for the daily dose of ICS (OR (95\% CI) 3.24 (1.56-6.76)), or when excluding the 64 participants with chronic bronchitis (OR (95 \%CI) 2.21 (1.31-3.72)). Furthermore, associations between neutrophil inflammation and poor asthma control remained significant with 
TABLE 2 Adjusted cross-sectional associations between neutrophilic or eosinophilic granulocyte patterns and asthma or asthma-related phenotypes in the second survey of the Epidemiological Study on the Genetics and Environment of Asthma

\begin{tabular}{|c|c|c|}
\hline & NEU ${ }^{\text {hi }}$ versus NEU lo $^{\text {lo }}$ & EOS $^{\text {hi }}$ versus EOS ${ }^{\text {lo }}$ \\
\hline Subjects $n / n$ & $92 / 382$ & $192 / 282$ \\
\hline Skin-prick test positivity \# & $0.91(0.49-1.70)$ & $1.13(0.67-1.90)$ \\
\hline Methacholine challenge ${ }^{\pi} \mathrm{PD}_{20} \leqslant 4 \mathrm{mg}$ & $1.60(0.75-3.40)$ & $2.21(1.24-3.97)^{+}$ \\
\hline At least one asthma attack in past 12 months & $1.55(0.98-2.46)$ & $1.48(0.99-2.21)^{\S}$ \\
\hline \multicolumn{3}{|l|}{ Nocturnal symptoms in past 12 months } \\
\hline Cough & $1.74(1.10-2.74)^{+}$ & $1.16(0.78-1.72)$ \\
\hline Chest tightness & $1.34(0.78-2.29)$ & $1.33(0.82-2.17)$ \\
\hline Shortness of breath & $1.38(0.87-2.17)$ & $1.22(0.83-1.80)$ \\
\hline \multicolumn{3}{|l|}{ Asthma control } \\
\hline Controlled & 1 & 1 \\
\hline Partly controlled & $2.88(1.70-4.87)^{+}$ & $1.32(0.87-2.02)^{f}$ \\
\hline Uncontrolled & $2.99(1.38-6.46)^{+}$ & $1.62(0.83-3.16)^{f}$ \\
\hline Asthma exacerbations in past 12 months & $2.19(1.07-4.50)^{+}$ & $0.81(0.48-1.38)$ \\
\hline Chronic cough & $2.20(1.15-4.21)$ & $1.22(0.68-2.17)$ \\
\hline Chronic phlegm & $1.73(0.84-3.59)$ & $1.40(0.78-2.54)$ \\
\hline Dyspnoea grade 3 & $1.71(0.91-3.22)$ & $1.26(0.73-2.18)$ \\
\hline \multicolumn{3}{|c|}{ 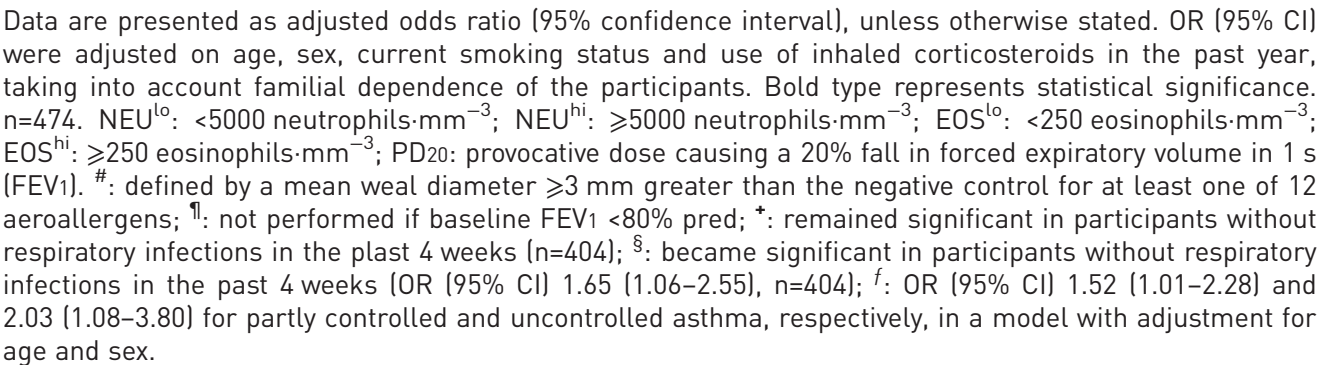 } \\
\hline
\end{tabular}

6040 cells $\cdot \mathrm{mm}^{-3}$ as the cut-off point for neutrophils (OR (95\% CI) 2.55 (1.26-5.18)), or with optimal cut-off points calculated using the ROC curve (online supplementary figure S1).

A high level of eosinophil inflammation was positively but inconsistently associated with poor asthma control (figure 2). The associations were significant after adjustment for age and sex, in participants without respiratory infections in the past 4 weeks, and in non-/ex-smokers. These associations did not remain significant after further adjustment for current smoking status and ICS treatment ( $\mathrm{p}$-values for Breslow-Day interaction test $<0.3$ ). Analyses performed with 300 cells $\cdot \mathrm{mm}^{-3}$ and 400 cells $\cdot \mathrm{mm}^{-3}$ as the cut-off points for eosinophils gave similar inconsistent findings (OR (95\% CI) 1.50 (1.01-2.24) and 1.51 $(0.91-2.50)$ for 300 cells $\cdot \mathrm{mm}^{-3}$ and 400 cells $\cdot \mathrm{mm}^{-3}$, respectively), due to reduced power because of the unbalanced distribution of participants between classes. Further adjustment for allergic sensitisation did not change the results.

Furthermore, participants with the mixed pattern (both high eosinophil and high neutrophil counts) had significantly higher risks of poor asthma control, asthma attack and asthma exacerbation compared to participants having only high eosinophil counts (table 3). Such findings were not found when comparisons were performed with participants having only high neutrophil counts.

\section{Granulocyte patterns at baseline and follow-up and phenotypic characteristics 12 years later in} longitudinal analyses ( $\mathrm{n}=242$ )

In our population, $46 \%$ of participants with the $\mathrm{NEU}^{\text {hi }}$ pattern at EGEA1, and $52 \%$ of those with the EOS $^{\text {hi }}$ pattern at EGEA1 continued to have the same pattern at EGEA2 (see online supplementary table S3 for the other patterns).

The NEU ${ }^{\text {hi }}$ pattern at EGEA1 was unrelated to the asthma phenotypes assessed at EGEA2 (table 4). However, participants with persistent $\mathrm{NEU}^{\mathrm{hi}}$ pattern $\left(\mathrm{NEU}^{\mathrm{hi}}\right.$ at EGEA1 and EGEA2) and those moving from $\mathrm{NEU}^{\text {lo }}$ to $\mathrm{NEU}^{\text {hi }}$ between the two surveys had poorer asthma control compared to those with the $\mathrm{NEU}^{\mathrm{lo}}$ pattern at both surveys (table 4 and figure 3). Similar findings were obtained when analyses were performed with 6040 cells. $\mathrm{mm}^{-3}$ as the cut-off point for neutrophils (OR (95\% CI) $3.21(0.73-14.04)$ ), or 

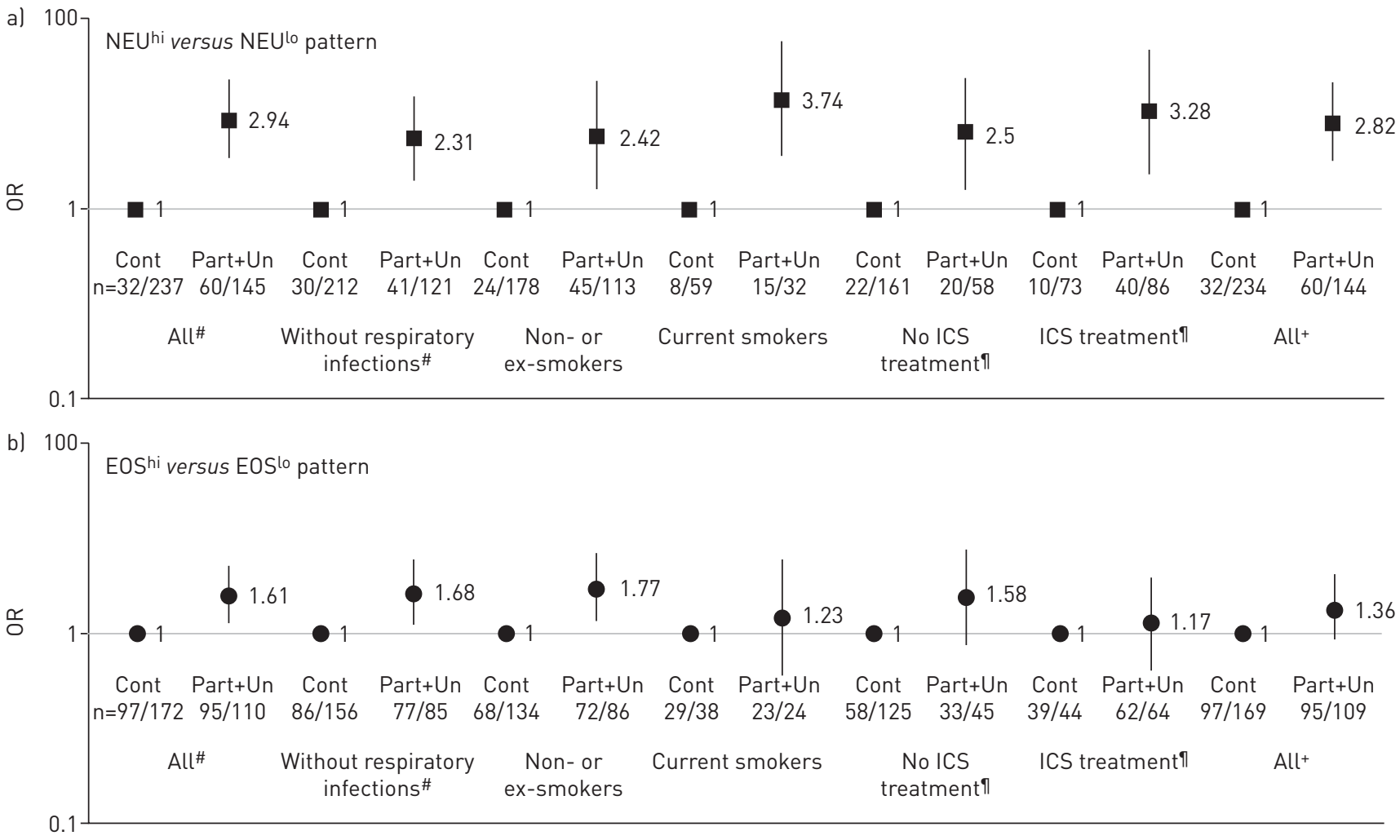

FIGURE 2 Cross-sectional association between a) neutrophilic or b) eosinophilic pattern and asthma control according to smoking status or inhaled corticosteroid (ICS) treatment in the past 12 months. ICS use was not available for four participants ( $=470$ ). NEU ${ }^{\text {hi }}$ : $\geqslant 5000$ neutrophils $\mathrm{mm}^{-3}$; NEU ${ }^{\text {lo }}$ : $<5000$ neutrophils $\cdot \mathrm{mm}^{-3}$; EOS ${ }^{\text {hi }}: \geqslant 250$ eosinophils. $\mathrm{mm}^{-3} ; \mathrm{EOS}^{\mathrm{lo}}:<250$ eosinophils.mm $\mathrm{mm}^{-3}$; cont: controlled; part: partly controlled; un: uncontrolled. ": odds ratios adjusted for age and sex; " : odds ratios adjusted for age, sex and current smoking status; ${ }^{+}$: odds ratios adjusted for age, sex, current smoking status and ICS treatment. Data are presented as n/n NEU hi $/$ NEU $^{\text {lo }}$ and EOS ${ }^{\text {hi }} /$ EOS $^{\text {lo }}$ in al and b), respectively.

with optimal cut-off points calculated using the ROC curve (online supplementary figure S1). No associations were found with the decline in lung function (table 5).

Participants with an EOS $^{\text {hi }}$ pattern at baseline had higher BHR at follow-up (table 4) than those with the EOS $^{\text {lo }}$ pattern. They also had higher total IgE level (geometric mean (95\% CI) 199 (153-259) IU.mL $\mathrm{mL}^{-1}$ versus $\left.101(80-128) \mathrm{IU} \cdot \mathrm{mL}^{-1}, \mathrm{p}<10^{-4}\right)$, and lower FEV1 at follow-up (table 5). Participants with persistent EOS $^{\text {hi }}$ patterns had higher BHR, higher total IgE level (270 (188-387) IU.mL ${ }^{-1}$ versus 115 (89-149) $\mathrm{IU} \cdot \mathrm{mL}^{-1}, \mathrm{p}<10^{-4}$ ) and lower FEV1 (table 5) than those with persistent $\mathrm{EOS}^{\text {lo }}$ patterns. Changes in eosinophilic patterns between EGEA1 and EGEA2 were unrelated to asthma control (figure 3). No associations were found with decline in lung function (table 5).

Analyses performed with 300 and $400 \mathrm{cells} \cdot \mathrm{mm}^{-3}$ as the cut-off points for eosinophils gave similar findings for the association with asthma control (OR (95\% CI) 2.10 (1.01-4.35) and 1.97 (0.83-4.65) for

TABLE 3 Associations between asthma control outcomes and exacerbations and mixed patterns (cross-sectional analyses)

\begin{tabular}{|c|c|c|c|c|}
\hline & $\mathrm{EOS}^{\mathrm{lo}} / \mathrm{NEU}^{\mathrm{hi}}$ & Mixed: EOS ${ }^{h i} / N E U^{h i}$ & EOS $^{\text {hi }} / \mathrm{NEU}^{\text {lo }}$ & Mixed: EOS $^{\text {hi }} / \mathrm{NEU}^{\mathrm{hi}}$ \\
\hline Subjects & 50 & 42 & 150 & 42 \\
\hline Methacholine challenge ${ }^{\#}$ PD $_{20} \leqslant 4 \mathrm{mg}$ & Ref. & $N A^{\pi}$ & Ref. & $2.89(0.77-10.8)$ \\
\hline Asthma attack in past 12 months $\%$ & Ref. & $2.23(0.87-5.71)$ & Ref. & $2.12(1.02-4.40)$ \\
\hline Asthma control: partly controlled/uncontrolled $\%$ & Ref. & $1.84(0.64-5.31)$ & Ref. & $3.46(1.54-7.76)$ \\
\hline Exacerbations in past 12 months $\%$ & Ref. & $0.79(0.29-2.18)$ & Ref. & $2.56(1.02-6.46)$ \\
\hline
\end{tabular}

Data are presented as $\mathrm{n}$ or OR $(95 \% \mathrm{Cl})$ and were adjusted for age, sex, current smoking status and inhaled corticosteroid use in the past year, and taking into account familial dependence of the participants. $n=474$. Bold type represents statistical significance. EOS $^{10}:<250$ eosinophils.mm ${ }^{-3}$; NEU hi: $\geqslant 5000$ neutrophils $\cdot \mathrm{mm}^{-3}$; EOS ${ }^{\text {hi }}: \geqslant 250$ eosinophils $\cdot \mathrm{mm}^{-3}$; NEU $\mathrm{No}^{\mathrm{lo}}:<5000$ neutrophils. $\mathrm{mm}^{-3}$; PD20: provocative dose causing a $20 \%$ fall in forced expiratory volume in $1 \mathrm{~s}\left(\mathrm{FEV}_{1}\right)$; NA: not available. ${ }^{\#}$ : not performed if baseline $\mathrm{FEV} 1<80 \%$ predicted; " ${ }^{\text {: }}$ due to smallest sample sizes. 
TABLE 4 Adjusted longitudinal associations between neutrophilic or eosinophilic granulocyte patterns at baseline (Epidemiological Study on the Genetics and Environment of Asthma (EGEA)1), or similar patterns at baseline and follow-up (EGEA1 and EGEA2) and asthma or asthma-related phenotypes at follow-up (EGEA2)

\begin{tabular}{|c|c|c|c|c|}
\hline & $\begin{array}{l}\text { NEU }{ }^{\text {hi }} \text { versus } \\
\text { NEU }^{\circ 0} \text { at baseline }\end{array}$ & $\begin{array}{l}\text { NEU }^{\text {hi }} \text { versus NEUlo at } \\
\text { baseline and follow-up }\end{array}$ & $\begin{array}{l}\text { EOS }^{\text {hi }} \text { versus EOS } \\
\text { at baseline }\end{array}$ & $\begin{array}{l}\text { EOS }^{\text {hi }} \text { versus EOS } \\
\text { baseline and follow-up }\end{array}$ \\
\hline Subjects $n / N$ & $52 / 190$ & $24 / 159$ & $106 / 136$ & $55 / 99$ \\
\hline Asthma attack in past 12 months & $0.90(0.48-1.69)$ & $1.22(0.52-2.87)$ & $1.02(0.61-1.71)$ & $1.30(0.67-2.54)$ \\
\hline \multicolumn{5}{|l|}{ Nocturnal symptoms in past 12 months } \\
\hline Cough & $0.80(0.42-1.50)$ & $0.93(0.37-2.30)$ & $0.63(0.36-1.09)$ & $0.65(0.31-1.39)$ \\
\hline \multicolumn{5}{|l|}{ Asthma control } \\
\hline Controlled & 1 & 1 & 1 & 1 \\
\hline Partly controlled/uncontrolled & $1.52(0.79-2.89)$ & $3.09(1.18-8.09)$ & $1.30(0.77-2.21)$ & $1.68(0.84-3.34)$ \\
\hline Exacerbations in past 12 months & $0.85(0.37-1.95)$ & $1.97(0.70-5.53)$ & $1.26(0.65-2.43)$ & $0.85(0.33-2.23)$ \\
\hline Chronic cough & $0.96(0.39-2.36)$ & $1.89(0.59-6.07)$ & $0.81(0.38-1.75)$ & $1.31(0.47-3.63)$ \\
\hline Chronic phlegm & $0.90(0.34-2.41)$ & $2.11(0.27-5.08)$ & $1.32(0.61-2.84)$ & $1.87(0.67-5.20)$ \\
\hline
\end{tabular}

Data are presented as $\mathrm{n} / \mathrm{N}$ or adjusted OR $(95 \% \mathrm{CI})$. OR $(95 \% \mathrm{Cl})$ were adjusted for age, sex and smoking at baseline, and taking into account familial dependence of the participants. $n=242$. Bold type represents statistical significance. NEU $\mathrm{N}^{\text {hi }} \geqslant 5000$ neutrophils.mm ${ }^{-3}$; NEU ${ }^{l o}:<5000$ neutrophils. $\mathrm{mm}^{-3}$; EOS ${ }^{\text {hi }}: \geqslant 250$ eosinophils. $\mathrm{mm}^{-3}$; EOS ${ }^{\mathrm{lo}}:<250$ eosinophils. $\mathrm{mm}^{-3}$; PD20: provocative dose causing a $20 \%$ fall in

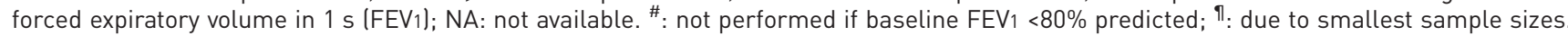

300 and 400 cells $\cdot \mathrm{mm}^{-3}$, respectively, in participants with a persistent $\mathrm{EOS}^{\text {hi }}$ pattern), although these findings were less significant due to reduced power.

\section{Discussion}

In the present study, we showed that blood neutrophil and eosinophil counts are relatively stable over 10 years, and that they are differently associated with clinical features of asthma: namely, the NEU ${ }^{\text {hi }}$ pattern was associated with exacerbations, poor asthma control and nocturnal symptoms, and the EOS ${ }^{\text {hi }}$ pattern was associated with higher IgE level, higher bronchial hyperresponsiveness and lower lung function.

Most of the participants with asthma included in the analysis were recruited in chest clinics as asthma cases, with a careful procedure set up to include true asthmatics using standardised and validated
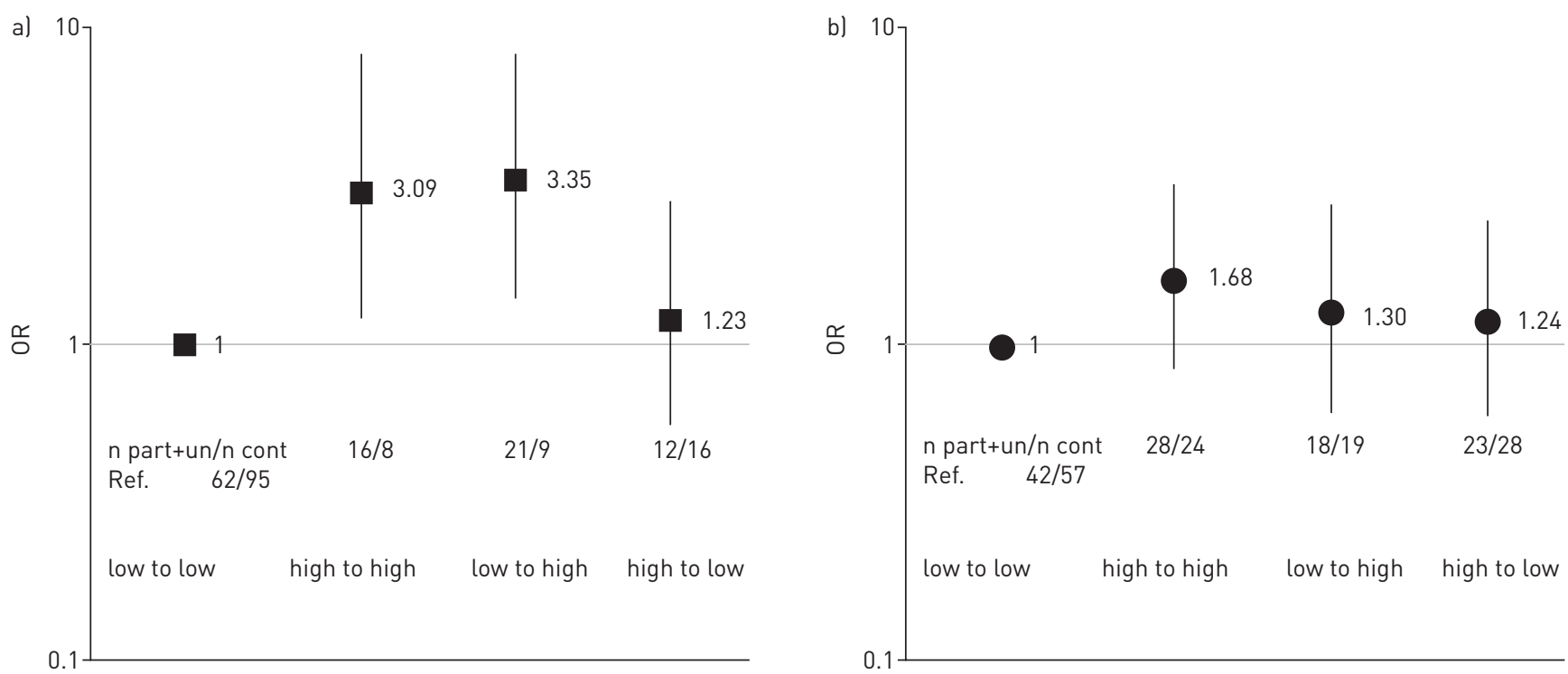

FIGURE 3 Longitudinal association between changes in a) neutrophilic or b) eosinophilic pattern between Epidemiological Study on the Genetics and Environment of Asthma (EGEA)1 and 2 and asthma control. Odds ratios (OR) were adjusted for age, sex and current smoking status at baseline. part: partly controlled; un: uncontrolled; cont: controlled. 
TABLE 5 Adjusted longitudinal associations between neutrophilic or eosinophilic granulocyte patterns at baseline (Epidemiological Study on the Genetics and Environment of Asthma (EGEA)1), or stable patterns between baseline and follow-up (EGEA1 and EGEA2) and lung function or lung function decline (EGEA2, $\mathrm{n}=242$ )

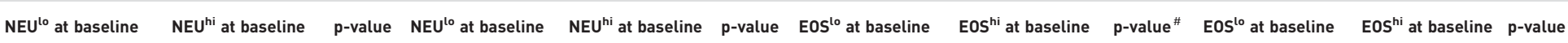
and follow-up and follow-up and follow-up

\begin{tabular}{|c|c|c|c|c|c|c|c|c|c|c|c|c|}
\hline Subjects $\mathbf{n}$ & 190 & 52 & & 159 & 24 & & 136 & 106 & & 99 & 55 & \\
\hline FEV $1 \%$ predicted ${ }^{\#}$ & $93.7(90.2-97.1)$ & $91.5(90.2-97.1)$ & 0.5 & $94.6(90.8-98.4)$ & $89.9(81.4-98.5)$ & 0.3 & $95.3(91.4-99.1)$ & $90.5(86.2-94.7)$ & 0.06 & $96.0(91.3-100.7)$ & $88.6(82.3-94.9)$ & 0.04 \\
\hline Change in FEV slope $\mathrm{mL} \cdot$ year $^{-1 \pi}$ & $-27.9(-35.0--20.8)$ & $-27.6(-37.8--13.7)$ & 0.7 & $-27.8(-35.4--20.1)$ & $-33.6(-51.1--16.1)$ & 0.5 & $-30.7(-38.6--22.7)$ & $-23.3(-32.0--14.6)$ & 0.2 & $-28.6(-38.2--19.0)$ & $-31.9(-44.5--19.4)$ & 0.6 \\
\hline
\end{tabular}

Data are presented as $\mathrm{n}$ or mean $(95 \% \mathrm{Cl})$. Means $(95 \% \mathrm{Cl})$ were adjusted for age, sex and smoking at baseline, and taking into account familial dependence of the participants. NEUhi:

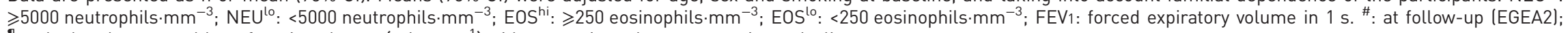

${ }^{7}$ : calculated as annual lung function change $\left(\mathrm{mL} \cdot \mathrm{year}^{-1}\right)$ with a negative value representing a decline. 
questionnaires. Others were recruited as first-degree relatives of asthmatic cases, based on anwers to questions on asthma diagnosis. This leads to a group of asthmatics with a wide range of severity and response to methacholine. No follow-up bias related to the asthma status and asthma-related phenotypes was shown in the EGEA study, and the adult asthmatics included in the present study are representative of the original study populations of asthmatic cases and their first-degree relatives with asthma. Furthermore, the association between high neutrophil inflammation and asthma control remained significant excluding participants with chronic bronchitis. The detailed respiratory questionnaire used in our study allowed to retrospectively assess asthma symptoms control following the principles of the GINA 2015 classification, although over a longer time frame ( 3 months rather than 1 month). The GINA 2015 definition takes into account daytime and night-time symptoms, use of reliever medication and activity limitation, but not lung function. Granulocyte patterns were defined according to eosinophil and neutrophil counts in blood, an easy approach in participants of all ages using standardised collection procedures. The approach of using blood markers to approximate airway inflammation has biological plausability since the infiltrating granulocytes in the airways derive from the bone marrow and access the airways via the circulation. The eosinophil count cut-off point used $\left(250 \mathrm{cells} \cdot \mathrm{mm}^{-3}\right)$ was most commonly used in epidemiology, close to the threshold value of 220 cells $\mathrm{mm}^{-3}$ found as the best compromise for predicting sputum eosinophil count $\geqslant 2 \%$ in 995 asthmatic adults [4], or for predicting uncontrolled airway eosinophilic inflammation in a population of 508 asthmatic adults [19]. The neutrophil cut-off point was the corresponding 75th percentile of the distribution in the EGEA adult population, and was very similar to the optimal cut-off points obtained from a ROC curve to assess asthma control.

The eosinophilic feature is recognised as a pivotal trait of asthma [28]. In the present study, we confirmed the well-documented associations of high blood eosinophil counts with high IgE level, increased BHR, lower FEV1 and more asthma attacks, as previously reported in general or occupational populations [29, 30], and in the EGEA study at baseline [6]. Furthermore, we found associations between $\operatorname{EOS}^{\text {hi }}$ and subsequent risk of increased BHR. However, we found inconsistent associations between $\operatorname{EOS}^{\text {hi }}$ and asthma control, and no clear association with subsequent risk of poor asthma control, or subsequent risk of asthma attacks or exacerbations, whatever the threshold. We found that high blood eosinophil counts were associated with exacerbations defined as asthma attack (considered as mild exacerbation), but not with exacerbations defined as admissions to hospital or to emergency or use of oral steroids (considered as severe exacerbation). Previously, higher blood eosinophil counts $\left(300-500\right.$ cells $\cdot \mathrm{mm}^{-3}$ ) have been associated with asthma attacks in 9223 adults from the National Health and Nutrition Examination Survey study [31] and in 3162 adults with asthma [32]. Regarding severe exacerbations, high blood eosinophil counts defined by a threshold of 400 or 300 cells $\cdot \mathrm{mm}^{-3}$ were associated with increased risk for future asthma exacerbations in a cohort of 2392 adults with persistent asthma [18], and in a very large cohort, 130248 patients with asthma with blood eosinophil counts $>300$ cells $\cdot \mathrm{mm}^{-3}$ defined as nine ascending eosinophil count categories (versus $\leqslant 200$ cells $\cdot \mathrm{mm}^{-3}$ ) had a greater rate of asthma exacerbations over the subsequent year [33]. Recently, the threshold of 400 cells $\cdot \mathrm{mm}^{-3}$ was reported as a risk factor for multiple exacerbations in the same cohort [34]. Asthma attack and asthma exacerbation may identify exacerbations of different severity, which might partly explain the differences in the associations found with blood eosinophils. The cut-off point for blood eosinophilia $\left(250\right.$ cells $\left.\cdot \mathrm{mm}^{-3}\right)$ applied in our study was in the lower range of the published cut-offs. Further, neither adjustment on blood neutrophilic inflammation, nor changes in granulocyte pattern over time were taken into account in these studies, and might explain part of the between-study discrepancies.

Regarding asthma control, previous studies have also shown quite different results to ours: lack of control of asthma was significantly associated with higher blood eosinophils in 111 patients with asthma [17] and blood eosinophilic inflammation $\left(\geqslant 400\right.$ cells $\left.\cdot \mathrm{mm}^{-3}\right)$ contributed to poor asthma control in 508 patients with asthma [19]. In a very large cohort of 130248 patients with asthma, blood eosinophil counts $>400$ cells $\cdot \mathrm{mm}^{-3}$ were associated with lower risk of achieving asthma control over the subsequent year [33]. Adjustment on blood neutrophilic inflammation was performed in one study [32], and changes in granulocyte pattern over time were not taken into account in these studies. In our study, the definition of asthma control differed from the definition used in previous studies that included either airflow variability or FEV1 level, and such phenotypic differences might explain part of the between-study discrepancies.

Variations over time of inflammatory markers in the blood or in the sputum are an important issue when trying to predict asthma evolution. Short-term and long-term stability of granulocyte patterns in sputum has been reported previously in adults $[9,35]$, mostly based on two sequential sputum samples. However, stable granulocyte patterns were found in only one-third of adults with moderate and severe asthma undergoing frequent (up to monthly) sputum induction over a 1-year period [36]. In our study, we reported variations over time of blood granulocyte patterns, and found that $\geqslant 50 \%$ of the participants retained the same pattern 12 years apart. In adults with severe asthma from the Dose Ranging Efficacy and 
Safety with Mepolizumab in Severe Asthma study, 85\% of those who had a screening blood eosinophil count of $\geqslant 150$ cells $\mu \mathrm{L}^{-1}$ retained the same pattern in the following year [37]. Recently, variations over time of blood eosinophilia in COPD patients have been studied and a good stability of the data 1 year apart was reported [15]. Overall, available data suggest that blood granulocyte patterns seem at least as stable as sputum patterns in adults with asthma.

To the best of our knowledge, only one study has investigated the role of blood neutrophils in asthma control in a very small sample of adults [38], reporting no differences between neutrophils from patients with well-controlled $(\mathrm{n}=11)$ versus suboptimally controlled asthma $(\mathrm{n}=7)$. In the present study, we found that the NEU ${ }^{\text {hi }}$ pattern was associated with poor asthma control according to the GINA 2015 classification, and that persistent $\mathrm{NEU}^{\text {hi }}$ pattern was associated with subsequent risk of poor asthma symptom control. Interestingly, as for eosinophilia, the associations between high blood neutrophil counts and exacerbations varied according to the phenotype we used. Neutrophilia was increased in ICS users in our study; this may be partly due to the inhibitory effect of corticosteroids on neutrophil apoptosis that may, in some settings, contribute to neutrophil activation, suggesting that corticosteroid treatment itself is likely to have some role in the development of neutrophilia [39]. The association that we observed between $\mathrm{NEU}^{\text {hi }}$ pattern and poor asthma control persisted after accounting for respiratory infections in the past 4 weeks, current smoking status and ICS treatment in the past year. To our knowledge, our study is the first to report that persistent $\mathrm{NEU}^{\text {hi }}$ pattern and change from $\mathrm{NEU}^{\text {lo }}$ to $\mathrm{NEU}^{\text {hi }}$ pattern were associated with poor asthma control (partly controlled or uncontrolled asthma) compared to other patterns. In the EGEA study, using unsupervised methods, we showed that blood neutrophil counts were the highest in the phenotype labelled "active treated adult-onset asthma" [40]. The latter phenotype showed similar characteristics as clusters that exhibited the highest sputum and blood neutrophil counts found in studies by Moore and colleagues [41, 42]. All these studies highlight the interest of using blood neutrophil counts when classifying adults with asthma. Overall, these results suggest that blood eosinophilia and neutrophilia may be associated with two particular and specific endotypes of asthma in adults, which may be related to different characteristics (symptoms, lung function and activity) of the disease. This is in line with new orientations for the clinical management of asthma, based on precise phenotyping and endotyping. New therapies targeting eosinophilic asthma are already available; however, due to the clinical importance of neutrophilic asthma, more research is needed to understand the basic mechanisms of neutrophilic asthma and offer opportunities of translational research for a more personalised and efficient treatment approach.

In conclusion, the present longitudinal study identified for the first time that blood granulocyte patterns are differently associated with subsequent asthma control outcomes in adults with asthma. More generally, this study adds evidence for the interest of blood eosinophils and neutrophils to help identifying adults with subsequent risk of asthma burden that could be targeted for specific therapies.

\section{Acknowledgements}

The authors thank all those who participated to the setting of the study and on the various aspects of the examinations involved: interviewers, technicians for lung function testing and skin prick tests, blood sampling, IgE determinations, coders, those involved in quality control, data and sample management and all those who supervised the study in all centres. The authors are grateful to the three CIC-Inserm of Necker, Grenoble and Marseille who supported the study and in which participants were examined. They are also grateful to the biobanks in Lille (CIC-Inserm), and at Annemasse (Etablissement Français du Sang) where biological samples are stored. They are indebted to all the individuals who participated, without whom the study would not have been possible.

EGEA cooperative group members are as follows:

Coordination: V. Siroux (epidemiology, principal investigator since 2013), F. Demenais (genetics), I. Pin (clinical aspects), R. Nadif (biology) and F. Kauffmann (PI 1992-2012). Respiratory epidemiology: M. Korobaeff (EGEA1) and F. Neukirch (EGEA1): Inserm U 700, Paris, France; I. Annesi-Maesano (EGEA1-2): Inserm U 707, Paris; F. Kauffmann, N. Le Moual, R. Nadif, M.P. Oryszczyn (EGEA1-2) and R. Varraso: Inserm CESP/U 1018, Villejuif, France; and V. Siroux: Inserm U 823, Grenoble, France. Genetics: J. Feingold: Inserm U 393, Paris; E. Bouzigon, F. Demenais and M.H. Dizier: Inserm U 946, Paris; and I. Gut and M. Lathrop: CNG, Evry, France. Clinical centres: I. Pin, C. Pison: Grenoble; D. Ecochard (EGEA1), F. Gormand and Y. Pacheco: Lyon, France; D. Charpin (EGEA1) and D. Vervloet (EGEA1-2): Marseille, France; J Bousquet: Montpellier, France; A. Lockhart (EGEA1) and R. Matran: Paris Cochin; E. Paty (EGEA1-2) and P. Scheinmann (EGEA1-2): Paris Necker; and A. Grimfeld (EGEA1-2) and J. Just: Paris-Trousseau. Data and quality management: J Hochez (EGEA1): Inserm ex-U155; N. Le Moual: Inserm CESP/U 1018, Villejuif; C. Ravault (EGEA1-2): Inserm ex-U780; N. Chateigner (EGEA1-2): Inserm ex-U794; and J. Quentin-Ferran (EGEA1-2): Grenoble.

\section{References}

1 Simpson JL, Scott R, Boyle MJ, et al. Inflammatory subtypes in asthma: assessment and identification using induced sputum. Respirology 2006; 11: 54-61.

2 Choi J-S, Jang AS, Park JS, et al. Role of neutrophils in persistent airway obstruction due to refractory asthma. Respirology 2012; 17: 322-329.

3 Fleming L, Tsartsali L, Wilson N, et al. Sputum inflammatory phenotypes are not stable in children with asthma. Thorax 2012; 67: 675-681. 
4 McGrath KW, Icitovic N, Boushey HA, et al. A large subgroup of mild-to-moderate asthma is persistently noneosinophilic. Am J Respir Crit Care Med 2012; 185: 612-619.

5 Hastie AT, Moore WC, Meyers DA, et al. Analyses of asthma severity phenotypes and inflammatory proteins in subjects stratified by sputum granulocytes. J Allergy Clin Immunol 2010; 125: 1028-1036.

6 Nadif R, Siroux V, Oryszczyn MP, et al. Heterogeneity of asthma according to blood inflammatory patterns. Thorax 2009; 64: 374-380.

Gibson PG. Tackling asthma phenotypes in community studies. Thorax 2009; 64: 369-370.

Nair P. What is an "eosinophilic phenotype" of asthma? J Allergy Clin Immunol 2013; 132: 81-83

Wenzel SE. Asthma: defining of the persistent adult phenotypes. The Lancet 2006; 368: 804-813.

10 Wenzel SE. Asthma phenotypes: the evolution from clinical to molecular approaches. Nat Med 2012; 18: 716-725.

11 Szefler SJ, Wenzel S, Brown R, et al. Asthma outcomes: biomarkers. J Allergy Clin Immunol 2012; 129: Suppl. 3, S9-S23.

12 Zhang XY, Simpson JL, Powell H, et al. Full blood count parameters for the detection of asthma inflammatory phenotypes. Clin Exp Allergy 2014; 44: 1137-1145.

13 Ortega HG, Liu MC, Pavord ID, et al. Mepolizumab treatment in patients with severe eosinophilic asthma. $N$ Engl J Med 2014; 371: 1198-1207.

14 Brightling CE, Chanez P, Leigh R, et al. Efficacy and safety of tralokinumab in patients with severe uncontrolled asthma: a randomised, double-blind, placebo-controlled, phase 2b trial. Lancet Respir Med 2015; 3: 692-701.

15 Pascoe S, Locantore N, Dransfield MT, et al. Blood eosinophil counts, exacerbations, and response to the addition of inhaled fluticasone furoate to vilanterol in patients with chronic obstructive pulmonary disease: a secondary analysis of data from two parallel randomised controlled trials. Lancet Respir Med 2015; 3: 435-442.

16 Hosoki K, Itazawa T, Boldogh I, et al. Neutrophil recruitment by allergens contribute to allergic sensitization and allergic inflammation. Curr Opin Allergy Clin Immunol 2016; 16: 45-50.

17 Volbeda F, Broekema M, Lodewijk ME, et al. Clinical control of asthma associates with measures of airway inflammation. Thorax 2013; 68: 19-24.

18 Zeiger RS, Schatz M, Li Q, et al. High blood eosinophil count is a risk factor for future asthma exacerbations in adult persistent asthma. J Allergy Clin Immunol Pract 2014; 2: 741-750.

19 Schleich FN, Chevremont A, Paulus V, et al. Importance of concomitant local and systemic eosinophilia in uncontrolled asthma. Eur Respir J 2014; 44: 97-108.

20 Kauffmann F, Dizier MH. EGEA (Epidemiological study on the Genetics and Environment of Asthma, bronchial hyperresponsiveness and atopy) - design issues. Clin Exp Allergy 1995; 25: Suppl. 2, 19-22.

21 Kauffmann F, Dizier MH, Annesi-Maesano I, et al. EGEA (Epidemiological study on the Genetics and Environment of Asthma, bronchial hyperresponsiveness and atopy) - descriptive characteristics. Clin Exp Allergy 1999; 29: Suppl. 4, 17-21.

22 Bouzigon E, Nadif R, Le Moual N, et al. Facteurs génétiques et environnementaux de l'asthme et de l'allergie: synthèse des résultats de l'étude EGEA. [Genetic and environmental factors of asthma and allergy: results of the EGEA study]. Rev Mal Respir 2015; 32: 822-840.

23 Kauffmann F, Dizier M-H, Pin I, et al. Epidemiological study of the genetics and environment of asthma, bronchial hyperresponsiveness, and atopy: phenotype issues. Am J Respir Crit Care Med 1997; 156: S123-S1129.

24 Burney PG, Luczynska C, Chinn S, et al. The European Community Respiratory Health Survey. Eur Respir J 1994; 7: 954-960.

25 Siroux V, Boudier A, Dolgopoloff M, et al. Forced midexpiratory flow between $25 \%$ and $75 \%$ of forced vital capacity is associated with long-term persistence of asthma and poor asthma outcomes. J Allergy Clin Immunol 2016; 137: 1709-1716.

26 Miller MR, Hankinson J, Brusasco V, et al. Standardisation of spirometry. Eur Respir J 2005; 26: 319-338.

27 Troussard X, Vol S, Cornet E, et al. Full blood count normal reference values for adults in France. J Clin Pathol 2014; 67: 341-344.

28 Bousquet J, Chanez P, Lacoste JY, et al. Eosinophilic inflammation in asthma. N Engl J Med 1990; 323: 1033-1039.

29 Pavord ID. Eosinophilic phenotypes of airway disease. Ann Am Thorac Soc 2013; 10: Suppl. S143-S149.

30 Pavord ID, Shaw DE, Gibson PG, et al. Inflammometry to assess airway diseases. Lancet 2008; 372: 1017-1019.

31 Malinovschi A, Fonseca JA, Jacinto T, et al. Exhaled nitric oxide levels and blood eosinophil counts independently associate with wheeze and asthma events in National Health and Nutrition Examination Survey subjects. J Allergy Clin Immunol 2013; 132: 821-827.

32 Tran TN, Khatry DB, Ke X, et al. High blood eosinophil count is associated with more frequent asthma attacks in asthma patients. Ann Allergy Asthma Immunol 2014; 113: 19-24.

33 Price DB, Rigazio A, Campbell JD, et al. Blood eosinophil count and prospective annual asthma disease burden: a UK cohort study. Lancet Respir Med 2015; 3: 849-858.

34 Price D, Wilson AM, Chisholm A, et al. Predicting frequent asthma exacerbations using blood eosinophil count and other patient data routinely available in clinical practice. J Asthma Allergy 2016; 9: 1-12.

35 Green RH, Pavord I. Stability of inflammatory phenotypes in asthma. Thorax 2012; 67: 665-667.

36 Al-Samri MT, Benedetti A, Préfontaine D, et al. Variability of sputum inflammatory cells in asthmatic patients receiving corticosteroid therapy: a prospective study using multiple samples. J Allergy Clin Immunol 2010; 125: $1161-1163$.

37 Katz LE, Gleich GJ, Hartley BF, et al. Blood eosinophil count is a useful biomarker to identify patients with severe eosinophilic asthma. Ann Am Thorac Soc 2014; 11: 531-536.

38 Tang FS, Foxley GJ, Gibson PG, et al. Altered innate immune responses in neutrophils from patients with welland suboptimally controlled asthma. Mediators Inflamm 2015; 2015: 219374.

39 Cowan DC, Cowan JO, Palmay R, et al. Effects of steroid therapy on inflammatory cell subtypes in asthma. Thorax 2010; 65: 384-390.

40 Siroux V, Basagaña X, Boudier A, et al. Identifying adult asthma phenotypes using a clustering approach. Eur Respir J 2011; 38: 310-317.

41 Moore WC, Hastie AT, Li X, et al. Sputum neutrophil counts are associated with more severe asthma phenotypes using cluster analysis. J Allergy Clin Immunol 2014; 133: 1557-1563.

42 Moore WC, Meyers DA, Wenzel SE, et al. Identification of asthma phenotypes using cluster analysis in the Severe Asthma Research Program. Am J Respir Crit Care Med 2010; 181: 315-323. 